LITERATURHISTORISCHE STUDIE 


\section{DIALOGUS IM MITTELALTER}

Die Abgrenzung eines Textkorpus des mittelalterlichen Dialogs birgt die Gefahr eines Zirkelschlusses in sich, denn sie setzt notwendigerweise ein Vorverständnis von Dialog voraus, das die Wahl der Abgrenzungskriterien bedingt. Ein solches Vorverständnis darf nicht aus dem antiken Dialog, der im Mittelalter kaum nachgeahmt wurde, gewonnen werden. Auch der Rückgriff auf die spätantiken Dialoge verbietet sich vorerst, denn die Kontinuität zwischen spätantiken und mittellateinischen Typen und Traditionen steht noch in Frage. Es gibt nur einen Ausweg aus diesem Dilemma: Es muss zuvor geklärt werden, welche Schriften mittelalterliche Autoren und Rezipienten als Dialoge ansahen und welche Merkmale und Eigenschaften sie mit ihnen in Verbindung brachten. Erst dann können angemessene Abgrenzungskriterien für das Korpus entwickelt werden.

Es ist freilich nicht einfach herauszufinden, wie dieses mittelalterliche Verständnis von Dialog geartet war. Eine spezifisch mittelalterliche Poetik gibt es so wenig wie eine Gattungstheorie, die normativ gewirkt hätte. Die Quellen, die uns zur Verfügung stehen, müssen mit Rücksicht auf ihren Kontext und ihre Funktionen bewertet werden. Rhetoriken und Poetiken tradieren Versatzstücke antiker Gattungstheorie und reflektieren nur bedingt die mittelalterliche Wirklichkeit ${ }^{1}$. Auch Glossare überliefern vorgefundene, aus dem ursprünglichen Kontext herausgerissene Erklärungen, die bisweilen unverständlich sind ${ }^{2}$. Accessus und Kommentare

\footnotetext{
${ }^{1}$ Vgl. Kindermann, „Gattungssysteme“, 303-304; Klopsch, Dichtungslehren, 111-120.

2 Vor allem ältere Glossare überliefern ein vielfältiges Material: abgeschriebene Glossen, Erklärungen aus antiken Glossographen und Kommentaren, Übersetzungen in die Volkssprachen. Erst ab dem 11. Jahrhundert ist die Entwicklung eines Systems zu beobachten, wobei allerdings zum Teil schwer verständliche Glossen weiter tradiert werden. Als Beispiel kann folgendes Interpretament zu dialogus im Liber glossarum (auch Glossarium Ansileubi genannt, aus Corbie, 8. Jahrhundert) dienen: capituli dictio delectabilis (Glossaria, Ed. Lindsay, Bd. 1, 28, 174). Vermutlich handelt es sich dabei um eine Randbemerkung, die nur im ursprünglichen Kontext verständlich war. Sie wird trotzdem noch von Papias aufgeführt (91). Ähnliches findet sich in einem Accessus zu Ciceros De amicitia, dessen ältester Textzeuge aus dem 12. Jahrhundert (Ende) stammt: Vocatur autem hic liber dragma, id est delectabile carmen (Accessus zu Ciceros De amicitia, Ed. Pellegrin, 292). Zur lexikographischen Literatur des Mittelalters vgl. Stotz, Bd. 1, 175-182; Codoñer, „Evolución“.
} 
entwickeln Klassifizierungen und Begriffe, die auf das Verständnis des kommentierten Autors abgestimmt sind und keine Allgemeingültigkeit anstreben ${ }^{3}$. Aussagen der Autoren sind wertvoll, aber verhältnismäßig selten. Ergiebiger ist die Titelgebung, doch auch sie verlangt eine kritische Untersuchung: Allzuoft gehen heute gebräuchliche Titel auf den ersten Druck oder auf einen neuzeitlichen Katalog zurück und reflektieren deshalb einen späteren Dialogbegriff ${ }^{4}$. Aus alledem folgt die Notwendigkeit, den mittelalterlichen Dialog nicht vom Wort, sondern von der Sache her anzugehen. Bei mittelalterlichen ,Definitionen' ist die Klärung ihres Kontextes und der Traditionen, aus denen sie schöpfen, unerlässlich. Das ist der Fall bei Isidors Dialogdefinition sowie bei den Klassifizierungen Konrads von Hirsau und Wilhelms von Conches. Sie werden deshalb einzeln interpretiert. Andere Aspekte des Dialogs (Vers oder Prosa, Personensprache, Bezug zur Diatribe) sind nur durch die Heranziehung und den Vergleich verschiedener Quellen zu klären. Auf diese Weise können Erkenntnisse gewonnen werden, die uns nicht nur zur Abgrenzung des Korpus, sondern auch zur historisch adäquaten Typisierung und Beschreibung der Dialogliteratur führen ${ }^{5}$.

\subsection{Dialogus bei Isidor}

Mittelalterliche Enzyklopädien sowie Rhetorik- oder Poetiklehren erwähnen den Dialog als Textsorte nicht. Wenn das Wort dialogus vorkommt, wie bei Gervasius von Melkley, bezeichnet es die Personensprache als rhetorisches Mittel, nicht die Dialogschrift ${ }^{6}$. Es gibt jedoch eine frühe

3 Rädle, „Literatur“, 224.

${ }^{4}$ Siehe unten 51-53. Nicht nur aus diesem Grund verbietet sich der Ausweg, das Korpus auf Texte mit dem Titel Dialogus zu beschränken. Viele der bekanntesten mittelalterlichen Dialoge tragen diesen Titel nicht, z.B. Abaelards Collationes, Anselms Cur Deus homo, das Periphyseon des Johannes Scottus Eriugena, das Dragmaticon des Wilhelm von Conches, um nur einige wenige zu nennen. Auch für die Frühe Neuzeit wurde die Titelvielfalt der Dialogschriften beobachtet (Ludwig, „Formen und Bezüge“, 61). Briesemeister vermerkt, dass Dialoge im 15. Jahrhundert auf der Spanischen Halbinsel sehr häufig den Titel tractatus / tra(c)tado tragen. Erst ab ca. 1529 bürgert sich eine Differenzierung zwischen diálogo und tratado ein (Briesemeister, „Humanistische Dialoge“, 191-193).

${ }^{5}$ Dieses historische Verständnis lässt Föcking, „Dyalogum“, 76-84, trotz einzelner wertvoller Beobachtungen zum Gebrauch des Wortes dialogus vermissen.

${ }^{6}$ Gervasius unterscheidet nicht zwischen der Personensprache im Drama und dem Gespräch als Textbestandteil: Color qui consistit in questione et responsione subdividitur in dialogum et subiectionem. Dialogus. Dialogus est sermo versatus inter duos, ut inter Didonem et Annam, sororem 
Ausnahme: Isidor von Sevilla (ca. 570-636) in seinen Etymologiae, einer der meistverbreiteten Enzyklopädien des Mittelalters.

Die fragliche Stelle befindet sich in Buch 6, das in den Editionen den Titel De libris et officiis ecclesiasticis trägt ${ }^{7}$. Der Aufbau des Buches ist ein gutes Beispiel für Isidors assoziative Vorgehensweise. Es beginnt mit der Inhaltsangabe der Bibelbücher, die zu einer Reihe Informationen zum Thema „Buch“ führt: eine kurze Geschichte der Bibliotheken, Informationen über die „Vielschreiber" (Varro, Didymus, Origenes, Hieronymus), eine Typisierung der Texte (hier befindet sich die Erwähnung des Dialogs), Techniken und Materialien der Buchherstellung. Die nächsten Kapitel knüpfen erneut an das erste Thema, die Bibel, an und behandeln den Kanon (kanonische Bibelbücher und konziliare Kanones). Es folgen die kirchlichen Festtage, wobei die Berechnung des Osterdatums erläutert wird. Zum Schluss definiert Isidor die kirchlichen Ämter. Kapitel 8, De opusculis, in dem der Dialog behandelt wird, beginnt folgendermaßen:

Opusculorum genera esse tria. Primum genus excerpta sunt, quae grece scolia nuncupantur; in quibus ea quae videntur obscura vel difficilia summatim ac breviter perstringuntur. Secundum genus omeliae sunt, quas Latini verbum appellant, quae proferuntur in populis. Tertium tomi, quos nos libros vel volumina nuncupamus. Omeliae autem ad vulgum locuntur, tomi vero, id est libri, maiores sunt disputationes ${ }^{8}$.

Diese ersten Sätze lassen bereits erkennen, dass opuscula hier eine breitere Bedeutung als ,Werke' hat. In dem Kapitel behandelt Isidor nämlich auch paratextuelle Elemente und Textformen, die einem anderen Text beigefügt oder untergeordnet sind (Scholien, Kommentare, Vorworte). Kapitel 8 ist daher eher eine Text- als eine Werktypisierung. Die erste Behauptung Isidors, es gäbe drei Sorten von Texten, suggeriert, dass alle weiteren Typen sich in diese Dreiteilung einfügen lassen. Dem ist jedoch nicht so. Isidor verallgemeinert hier eine Einteilung der Werke

suam, sic: „Anna, soror, morior. Qua re? Quia vivo. Quid inde? Talis enim vite vespere vita foret". Et illud: „,quid fers?? Poma fero. Quot? VII. Da mihi! nolo“. Huiusmodi contingit plenius invenire in Seneca tragediarum (26, 5-14, dazu Kommentar LV-LVII, vgl. auch Klopsch, 141).

7 Dieser Titel ist wohl nur bei den neuzeitlichen Editoren (Arévalo, Lindsay) zu lesen. Chaparro ist der Meinung, dass der Originaltitel De sanctis Scripturis lautete und auf den thematischen Aufbau hinwies: zentral ist die Behandlung der Bibelbücher, von ihr leitet Isidor zu verwandten Themen über. Vgl. Chaparro, „Observaciones“.

${ }^{8}$ Text aus Chaparro, „Isidoro“, 176 (basierend auf den Vorarbeiten zu einer Neuedition von orig. 6,8). 
des Origenes, die auf Hieronymus zurückgeht ${ }^{9}$, und kommt in seiner weiteren Auflistung nicht mehr darauf zurück. Diese Aneinanderreihung unterschiedlicher, zum Teil sich widersprechender Bestandteile ist für seine Arbeitsweise charakteristisch. Gleich darauf und ohne erkennbare Anknüpfung wird der Dialog erwähnt:

Dialogus est conlatio duorum vel plurimorum, quem Latini sermonem dicunt, nam quos Greci dialogos vocant, nos sermones vocamus. Sermo autem dictus quia inter utrumque seritur, unde in Virgilio: „Multa inter se serebant". Tractatus est unius rei multiplex expositio, eo quod trahat sensum in multa sentiendi contrectando secum. Differt autem sermo, tractatus et verbum: sermo enim alteram eget personam, tractatus specialiter ad se ipsum est, verbum autem ad omnes, unde et dicitur „Verbum fecit ad populum $" 10$.

Auch hier geht Isidor assoziativ vor und reiht kommentarlos Unterschiedliches aneinander. Er beschreibt zuerst den Dialog als Gespräch und verwendet dazu das Wort sermo, das die ungezwungene Unterhaltung bezeichnet ${ }^{11}$. Die etymologische Erklärung, die wohl aus Varro kommt ${ }^{12}$, und das Beispiel aus Vergil erläutern diese Bedeutung. Aus dem Kontext wird allerdings klar, dass hier ein verschriftlichtes

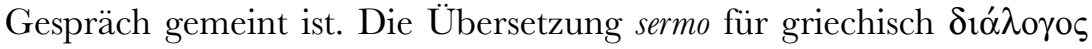
als Titel eines Werkes ist nämlich seit Cicero bezeugt, der die platonischen Dialoge sermones Platonis nannte ${ }^{13}$. Es folgt die Definition des Traktats und eine neue Dreiteilung, in der zwischen sermo, tractatus und verbum unterschieden wird. Sie richtet sich augenscheinlich nach der angesprochenen Person: Im sermo spricht der Autor einen anderen an, im tractatus sich selbst, im verbum die Allgemeinheit ${ }^{14}$. Es stellt sich jedoch die Frage, warum gerade diese drei Textformen gegeneinander

\footnotetext{
${ }^{9}$ Fontaine, Isidore, 751-752.

${ }^{10}$ Bei Vergils Zitat handelt es sich um den leicht abgeänderten Vers Aen. 6,160: multa inter sese vario sermone serebant.

${ }^{11}$ Vgl. Lévy, „La conversation“, 399-402.

12 VARRo, ling. 6, 64: sermo opinor est a serie, unde serta.

${ }_{13}$ Z.B.: Gia. orat. 3, 60. Vgl. Lévy, 402-403.

${ }^{14}$ Diese Passage erinnert an die Klassifizierung der verschiedenen Zuhörerschaften des Redners bei Perelman / Olbrechts-Tyteca: „C'est donc la nature de l'auditoire auquel des arguments peuvent être soumis avec succès qui détermine dans une large mesure et l'aspect que prendront les argumentations [...] Nous trouvons trois espèces d'auditoires, considérés comme privilégiés à cet égard, tant dans la pratique courante que dans la pensée philosophique. Le premier, constitué par l'humanité tout entière [...] que nous appellerons l'auditoire universel; le second formé, dans le dialogue, par le seul interlocuteur auquel on s'adresse; le troisième, enfin, constitué par le sujet lui-même, quand il délibère ou se représente les raisons de ses actes" (La nouvelle rhétorique, 39-40).
} 
abgegrenzt werden. Die Antwort ist in der spezifischen Bedeutung der drei Wörter bei den Christen zu suchen: Alle drei stehen für ,Predigt ${ }^{615}$. Isidor hat in diesen ersten Zeilen drei Wörter für "Predigt' benutzt, wenngleich er bei sermo und tractatus vorerst eine andere Verwendung erläutert hat. Nun versucht er, diese zum Teil synonymen Begriffe zu differenzieren. Die Definition von sermo passt für beide bisher erwähnten Bedeutungen des Wortes, ,Gespräch“ und ,Ansprache'. Die Frage, die sich dabei stellt, ist, ob hier sermo immer noch dialogus entspricht, d.h., ob dialogus für Isidor ebenso eine Ansprache bezeichnen kann. Darauf werden wir zurückkommen ${ }^{16}$.

Isidors Erklärung von Dialog als Gespräch wird um die Mitte des 11. Jahrhunderts von Papias in seinem Elementarium doctrinae erudimentum (bekannt als Vocabulista) unter dem Lemma sermo aufgenommen ${ }^{17}$. Der unbekannte Verfasser eines Accessus zu Horaz scheint sich ebenfalls darauf zu beziehen, wenn er das Wort sermo erläutert, er arbeitet jedoch beide Bedeutungen klarer als Isidor heraus ${ }^{18}$. Hugo von St. Victor, der einige Informationen aus orig. 6,8 nimmt, lässt die Bedeutung ,Ansprache $^{6}$ weg $^{19}$. Isidors Definition findet sich verkürzt noch in den ersten Jahren des 15. Jahrhunderts im Vocabularius Ex quo ${ }^{20}$.

15 Sermo wird gelegentlich in den Bibelübersetzungen für eine Ansprache gebraucht und ist im 4. Jahrhundert in der Bedeutung, Predigt' endgültig etabliert (vgl. den Artikel von Grégoire; bereits als Titel der horazischen Satiren fungiert sermo als lateinische Entsprechung von griechisch $\delta 1 \alpha \tau \rho ß \beta \dot{n}$, vgl. Knoche, Die römische Satire, 49). Tractatus bezeichnet zuerst die schriftliche Erörterung eines Themas, wird aber ab Augustinus ebenfalls für die mündliche Erörterung verwendet (vgl. den Artikel von Siniscalco; zu sermo und tractatus vgl. Mohrmann, „Praedicare“, 71-73, und Tovar Paz, „Empleo léxico"). Verbum ist in dieser Bedeutung nicht so häufig wie sermo oder tractatus, aber auch gelegentlich zu finden (vereinzelt in den Bibelübersetzungen, vgl. Grégoire, 3157, auch bei Isidor am Beginn dieses Kapitels als Übersetzung von griechisch ó $\mu \imath \lambda$ í $\alpha$; Beispiele bei anderen christlichen Autoren: Vict. Vit. 2,8, Greg. Tvr. Franc. 10,1; bereits im klassischen Latein war verbum facere eine lexikalisierte Wendung, um eine Ansprache vor dem Senat zu bezeichnen, vgl. Roesch, „Les emplois“).

16 Siehe unten 54-55.

17 Sermo plurimorum uerborum oratio, est a serendo dictus. quod nos cum praepositione dicimus a disserendo. unde sermo sancti augustini id est disertio dicitur. sermo collatio duorum uel plurimorum est quem graeci dialogum dicunt dictus quia inter utrunque seritur: eget enim alterius personae. sermocinari inter se fari: colloqui. sermocinor sermocinaris (316).

18 Konrad von Hirsau, Dialogus super auctores, Ed. Huygens, 51, 56-58: Et dicitur sermo quod inter eum et ad minus inter duos seritur et ad presentem personam fit: unde et predicatio episcoporum recte dicitur sermo.

${ }_{19}$ Hugo von St. Victor, Didascalicon, Ed. Buttimer, 4,16: dialogus est collatio duorum vel plurimorum quem Latini sermonem dicunt. sermo autem dictus, quia seritur inter utrumque.

${ }^{20}$ D 292 (Bd. 3, 768): Dyalogus est sermo duorum, in einigen Handschriften weiter expliziert: scilicet opponentis et respondentis. Zur Datierung vgl. Grubmüller, Art. „Vocabularius“. 
Ein weiterer Aspekt von Isidors Auslegungen muss angesprochen werden, nämlich, welchem Bereich der Schriftlichkeit er den Dialog zuordnet. In Buch 6, Kapitel 8 werden neben den bereits genannten Textsorten folgende definiert: commentaria, apologeticum, panegyricum, fasti, proemium, praecepta, parabolae, problemata, quaestio, argumentum und epistola. Aber orig. 6,8 ist nicht der einzige Abschnitt von Isidors Werk, in dem eine Texttypisierung entworfen wird. In Buch 1, Kapitel 38 (de prosa), 39 (de metris), 40 (de fabula), 41 (de historia) werden ebenfalls verschiedene Textsorten erwähnt: in cap. 39 carmen heroicum, elegiacum und bucolicum, sowie hymni, epithalamia, threni, epitaphium, epigramma, epodon und centones; in cap. 41 ephemeris, calendaria und annales. In Buch 1 und Buch 6 werden nicht dieselben Textsorten nach unterschiedlichen Kriterien klassifiziert, sondern es handelt sich um zwei Bereiche der Schriftkultur²1. In orig. 1 findet sich die Aufstellung der Textsorten im Anschluss an die Grammatik, die mit einer Einführung in Tropen und Figuren abschließt. Der Aufbau spiegelt die schulische Praxis wider: Das Erlernen der Grammatik und vor allem der Stilmittel wurde direkt an den Autoren geübt ${ }^{22}$. Im Buch 1 geht es demzufolge um die Werke, die im Schulunterricht gelesen und kommentiert wurden. Orig. 6,8 hingegen behandelt schulische Textformen (Scholien, Quaestiones, Problemata, Kommentare) ${ }^{23}$ und Pastoralschriften $^{24}$ zur Erbauung und Bildung des christlichen Volkes (Predigten, Briefe, apologetische Schriften). Es handelt sich demnach um Gebrauchsliteratur, die situations- und zweckgebunden ist; dies sind vor allem didaktische Schriften, aber auch Fasti und panegyrische Reden ${ }^{25}$. In diesem Bereich verortet Isidor den Dialog. Dies lässt vermuten, dass er an Dialoge mit didaktischer oder apologetischer Ausrichtung dachte. Autoren, die er kannte und ausgiebig zitierte, wie Hieronymus und Augustinus, hatten solche Dialoge geschrieben.

${ }^{21}$ Vgl. Chaparro, „Isidoro“.

${ }^{22}$ Vgl. Fontaine, Isidore, 157-158. Dass der Autorenkommentar zum Grammatikunterricht gehörte, führte zu einem gegenseitigen Einfluss zwischen Grammatiklehrbüchern und Autorenkommentaren, vgl. Schindel, „Wechselwirkungen“.

${ }^{23}$ Diese ,Schul- und Regestenliteratur" spielte wohl eine wichtige Rolle als Quelle für Isidors Enzyklopädie, vgl. Fontaine, Isidore, 750-762.

${ }^{24}$ Obwohl einige Bezeichnungen sich auf Reden beziehen (Predigten, panegyrische Reden, z. T. Apologie), ist hier die Verschriftung gemeint, wie der Titel De opusculis nahe legt.

${ }^{25}$ Codoñer betont die Praxisorientierung von orig. 4-6: Diese Bücher behandeln „materias de aplicación práctica, que es necesario conocer a todo personaje que deba enfrentarse a problemas de cualquier tipo en el siglo VII“ („Isidorus“, 297). 


\subsection{Dialogtypisierungen bei Konrad von \\ Hirsau und Wilhelm von Conches}

Zwei Autoren des 12. Jahrhunderts, Konrad von Hirsau (ca. 1070-1150) und Wilhelm von Conches (ca. 1080-1154), entwarfen Dialogtypisierungen; allerdings zeigt der Kontext, dass sie damit vor allem ältere, in der Schule kommentierte Werke beschreiben wollten. Obwohl die zeitgenössische Dialogliteratur sie nicht (oder nicht primär) interessierte, sollten ihre Ausführungen sorgfältig gelesen und kommentiert werden, denn diese Autoren haben sich nicht nur theoretisch mit dem Dialog beschäftigt, sondern auch selber Dialogschriften verfasst.

Konrad von Hirsau versammelte Materialien aus älteren Accessus und Kommentaren zu Schulautoren und organisierte sie als Dialog zwischen Lehrer und Schüler. Sein Dialogus super auctores bespricht die Autoren in der ungefähren Reihenfolge, in der sie in der Schule behandelt wurden ${ }^{26}$. Bei der Einführung zu den zwei Dialogen Ciceros, die im Mittelalter bevorzugt gelesen wurden, Cato maior de senectute und Laelius de amicitia, entwirft Konrad eine Klassifizierung von Dialogen oder vielmehr eine Typisierung der Autorintentionen:

Omnis autem dialogus fit tribus modis vel causis: fit enim vel causa maioris confirmationis, sicut in dialogo Gregorii et Petri, vel causa recreationis et delectationis, sicut invenitur in poetis, vel causa auctoritatis ut fides habeatur sermoni, quem auctentica persona facit ${ }^{27}$.

Von diesen drei Funktionen der Dialogform bereitet die Erklärung der letzten die geringsten Interpretationsprobleme. Sie bezieht sich auf die kommentierten Dialoge, in denen Cicero Personen auftreten lässt (Cato, Laelius), die mit besonderer Autorität über das behandelte Thema reden können. Diese Funktion der Dialogform wurde von Cicero selbst thematisiert

... omnem autem sermonem tribuimus non Tithono ut Aristo Cius (parum enim esse auctoritatis in fabula), sed M. Catoni seni, quo maiorem auctoritatem haberet oratio ${ }^{28}$.

und ebenfalls in zwei Accessus zu Ciceros De amicitia aufgenommen:

${ }^{26}$ Vgl. Tunberg, „Conrad of Hirsau“.

${ }^{27}$ Konrad von Hirsau, Dialogus super auctores, Ed. Huygens, 103, 972-976.

28 Gic. Cato, 1. 
... in hoc libro Lelium inducit de amicitia disputantem, duosque generos ipsius Fannium et Scevolam Lelium interrogantes. Nulla enim, sicut idem ait, persona visa est sibi ad tractandum amicitiam magis idonea quam eius qui et verus amicus fuit et, ob amicitiam, magnam gloriam acquisivit [...] Procul dubio opus suum autenticum reddit itemque lectorem docilem, ubi sermonem Lelii habitum de amicitia $\operatorname{dicit}^{29} \ldots$

Notandum est etiam quod comendatum hoc opus per personam inventoris, relatoris et scriptoris. Ad ultimum per personam inventoris quia per Lelium, ac si dicat: credendum est huic operi quia fuit inventum a Lelio, qui sapientissimus ab omnibus habebatur, quae hoc non inveniret nisi dignum omnibus bonis hoc esse cognosceret [...] Hoc autem genus carminis ubi personae introducuntur apud antiquos autenticum erat ${ }^{30}$.

Bei der zweiten Funktion (causa recreationis vel delectationis) ist es nicht klar, ob Konrad an Gedichte in Dialogform denkt oder eher an die Gespräche in direkter Rede, die Bestandteil eines Gedichtes sein können. Letzteres erscheint wahrscheinlicher, da Konrad die Eclogen Vergils und die Ecloga Theoduli kommentierte und beide Werke nicht dialogi sondern eclogae nennt. Die darin enthaltenen Gespräche nennt er sermones oder altercationes $^{31}$. Die angeführte Begründung, dass die Gesprächsform für Abwechslung und Unterhaltung sorgt, ist allerdings auch bei Dialogautoren geläufig ${ }^{32}$.

Die erste Kategorie (causa confirmationis) bezieht sich ausdrücklich auf die Dialogi des Gregorius Magnus. Mit confirmatio ist wohl nicht Bekräftigung oder Bestätigung der Aussagen im Sinne von Verleihung einer größeren Autorität gemeint - Gregorius ist sowohl Autor als auch Figur der Dialogi, er hätte seinen Ausführungen dieselbe Autorität in einem Traktat verleihen können -, sondern eher die Bestärkung im Glauben

\footnotetext{
${ }^{29}$ Accessus III (Accessus zu Ciceros De amicitia, Ed. Pellegrin, Text 290-294, hier 292), ältester Textzeuge aus dem 12. Jahrhundert (Ende).

${ }^{30}$ Erweiterte Fassung von Accessus I, überliefert in einer Handschrift aus dem 15. Jahrhundert (Accessus zu Ciceros De amicitia, Ed. Pellegrin, Text 281-286, hier 285-286).

31 Konrad von Hirsau, Dialogus super auctores, Ed. Huygens, 94, 705-706: Introducit autem Theodolus duas personas altercantes, terciam de duarum dictis iudicantem; dial. 120, 1511-1513: ... quia non solum in hoc opere armentariorum, sed etiam opilionum caprariorumque sermones, altercationes et cantica describuntur.

32 Siehe z. B. die Zitate aus Anselms Cur Deus homo, unten 44, aus Michaels von Prag Dialogus, unten 45, aus Wyclifs Dyalogus, unten 46, Stephanardus de Vicomercato, De apprehensione (R35), prol., Ed. Borgnet 555: De apprehensione ac apprehensionis modis seu diversitatibus disserens, disputationis seriem per dialogum prosecutus sum, ut ex tractandi modo legentibus fastidium magis tollatur, et studii levetur onus und Giovanni Conversino, Violatae pudicitiae narratio (R71c), Ed. Wolfer 332: In hac idcirco dyalogi tenore proceditur, quo suavior interrogacione subiecta locupletiorque dicendi series proveniret.
} 
und im glaubenskonformen Leben, die Gregorius seinem Gesprächspartner Petrus durch das Vorbild der Heiligen vermittelt. Eine solche aufbauende Unterweisung ist im monastischen Umfeld eng mit der Mündlichkeit verknüpft, wie sie in der monastischen Predigt und in dem persönlichen Gespräch des erfahrenen Mönches mit dem Novizen praktiziert wurde ${ }^{33}$.

Für Konrad gibt es demnach drei verschiedene Funktionen der Dialogform: Bestärkung, Unterhaltung und Autorisierung der Aussagen. Die von ihm herangezogenen Beispiele werfen eine Frage auf, nämlich, ob er Gedichte in Dialogform ebenfalls als dialogi ansieht. Dieser Frage werden wir mit Unterstützung anderer Quellen nachgehen ${ }^{34}$.

Eine zweite Klassifizierung von Dialogen stammt von Wilhelm von Conches (ca. 1090-ca. 1154), Lehrer an der Kathedralschule von Chartres $^{35}$. Er verfasste Glossen zu verschiedenen Werken und eine Philosophia, in der er eine systematische Darstellung des Wissens versucht, die ihm einen Häresieverdacht eintrug. Wilhelm verließ aus nicht geklärten Gründen sein Magisteramt und kam an den Hof von Geoffrey Plantagenet, Graf von Anjou und Herzog der Normandie, als Erzieher von dessen Sohn Henri, des späteren Königs Heinrich II. von England. Dort verfasste er ein zweites philosophisches Werk, das Geoffrey von Anjou gewidmet ist. In ihm entwickelt er Ansätze aus der Philosophia weiter und behandelt Fragen der Naturphilosophie als Dialog zwischen einem Dux und einem Philosophus sine nomine. Das Werk trägt in der Überlieferung verschiedene Titel, unter ihnen Dragmaticon philosophiae, eine Bezeichnung, die auf den Autor zurückgehen könnte. Er bezieht sich jedenfalls im Text auf sein eigenes Vorgehen mit den Worten dragmatice distinguemus ${ }^{36}$.

Wilhelms Dialogtypisierung findet sich an drei verschiedenen Stellen seiner Werke. Unter den Glossen zu Priscians Institutiones und zu Boethius' Consolatio lautet sie folgendermaßen:

Sunt enim tria genera collocutionum: didascalicum, id est magistri ad discipulum; didascalus enim est magister. Tale est in hoc opere in quo

${ }^{33}$ Dazu siehe unten 84.

34 Siehe unten $51-54$.

${ }_{35} \mathrm{Zu}$ Wilhelms Leben und Werk vgl. Wilhelm von Conches, Dragmaticon, Ed. Ronca, „Introduction“, xvII-xxII; Speer, Die entdeckte Natur, 130-138; Speer, „Ratione duce“, 215-219.

${ }_{36}$ Zur Frage des Titels vgl. Wilhelm von Conches, Dragmaticon, Ed. Ronca, „Introduction", $\mathrm{XI}^{-} \mathrm{XVI}$. 
Philosophia magistra loquitur cum Boetio discipulo. Est aliud dragmaticon inter interrogantem et respondentem; dragma enim interrogatio est. Tertium est enarratiuum quod continua oratione inter loquentem et audientem $\mathrm{fit}^{37}$.

Wilhelm nennt zwar die solchermaßen klassifizierten Texte collocutiones und nicht dialogi, es ist trotzdem davon auszugehen, dass er an verschriftete Gespräche denkt. In den Glosae ad Priscianum fehlt der Satz, der sich auf die Consolatio bezieht (Tale ... discipulo) ${ }^{38}$. Die Klassifizierung findet sich auch in den Glosae super Platonem (zu Calcidius' Übersetzung des platonischen Dialogs Timaeus), allerdings nur in einer Handschrift aus dem 15. Jahrhundert, die einen stark erweiterten und interpolierten Text überliefert ${ }^{39}$. Dort ist sie in dieser Form zu lesen:

Sed nota quod, cum narratio alia in personis, alia in negotiis versetur, ista in utrisque vertitur. In negotiis est quando sine introductione personarum solum narratur negotium. In personis ubi in negotii narratione nulla est interpositio persone. Hoc vero genus dicitur collocutio. Huius sunt tres species. Est enim inter interrogantem et respondentem, que dicitur dragmaticon - dragma enim interrogatio est - quod huiusmodi fuit inter Aquinum et Calcollum. Alia inter magistrum et discipulum, et est didascalicon, ut inter Donatum et discipulum, vel Catonem et filium. Alia est inter audientem et narrantem, qualis est in Macrobio, et hoc est enarneticon, id est enarrativum. Genus huius narrationis que in personis est quando in quadam parte loquuntur voce alterna, dicitur amotheron id est vicarium ${ }^{40}$.

Der Text, der vor allem am Anfang und Ende konfus wirkt, ist in keiner anderen Handschrift der Glosae super Platonem zu lesen, auch nicht in verkürzter Form. Trotzdem stammt der Grundgedanke (die Dialogtypisierung) von Wilhelm, wie die Parallelen mit dem ersten Zitat zeigen. Die Beispiele könnten wiederum spätere Erweiterungen sein; gerade die Erwähnung Donats sowie die Bezeichnung enarneticon (ein Schreiberfehler für ermeneuticum?) für das genus enarrativum lassen vermuten, dass der Redaktor dieses Textes die Dialogtypologie nicht direkt aus

\footnotetext{
${ }^{37}$ Glosae super Boetium, Ed. Nauta, liber I, prosa 1, pp. 17-18, lin. 16-24.

${ }^{38}$ Der Abschnitt wurde von Ronca ediert (Wilhelm von Conches, Dragmaticon, Ed. Ronca, „Introduction“, XIII).

${ }^{39}$ Wilhelm von Conches, Dragmaticon, Ed. Ronca, „Introduction“, XIII-XIV.

${ }^{40}$ Wilhelm von Conches, Glosae super Platonem, Ed. Jeauneau, Appendix 1, 304, Text der restlichen Hss., ebda. 71.
} 
Wilhelm, sondern aus Johannes Balbi hatte ${ }^{41}$. Am überzeugendsten ist das Beispiel für das genus dragmaticon. Die Namen scheinen in der Überlieferung verdorben zu sein und könnten ursprünglich Alcuinum et Carolum gelautet haben. Die Dialoge, in denen Alkuin Karl dem Großen die Rhetorik und die Dialektik erläutert, inszenieren nämlich die gleiche Konstellation Lehrer-Dienstherr wie Wilhelms Dragmaticon und sind ebenfalls durch Fragen und Antworten gegliedert. Besonders problematisch sind hingegen die Beispiele für das genus didascalicum, da sie scheinbar nahelegen, dass ein Text ohne Sprecherzuweisung (Donats Grammatik) oder gar ein Text, der sich als Ansprache gibt (die Disticha Catonis) als collocutio zu gelten haben. In diesem Fall ist es ratsam, vom ersten, gesicherten Text und von Wilhelms Beispiel (Boethius' Consolatio) auszugehen.

Wilhelms Darstellung des genus didascalicum als Unterhaltung zwischen Lehrer und Schüler dürfte auf eine Aussage des Servius in seinem (im Mittelalter eifrig gelesenen) Kommentar zu Vergils Georgica zurückgehen:

... et hi libri didascalici sunt, unde necesse est, ut ad aliquem scribantur, nam praeceptum et doctoris et discipuli personam requirit ${ }^{42}$.

Gerade in Bezug auf die Consolatio philosophiae wurde diese Aussage mehrfach zitiert, zum Beispiel von Johannes Balbi, der unter genus didascalicum die Redeweise des Lehrers (in diesem Fall Philosophia) erkennt ${ }^{43}$. Wer die Beispiele in den Glosae super Platonem einfügte, dachte offensichtlich an die Schulbücher für den Elementarunterricht. Der Wortlaut in Servius' Satz konnte jedoch so verstanden werden, als wäre ein Zwiegespräch damit gemeint. Das ist Wilhelms Auslegung, mit der er freilich nicht allein steht. Auch Wilhelm von Aragon (13. Jahrhundert, zweite Hälfte) äußert sich ähnlich:

Talis autem modus tractandi in genere dicitur didascalicus in quo duplex persona confingitur, scilicet docti et docentis, aut laborantis eciam et medentis ${ }^{44}$.

\footnotetext{
${ }^{41}$ Ronca schlägt als Korrektur epangelticon vor. Zum Text des Johannes Balbi siehe unten 43-44.

${ }^{42}$ SERv. georg. praef. p. 129, 9.

${ }^{43}$ Johannes Balbi, Catholicon, s. v. Didascalus: . . unde genus loquendi magistri ad discipulum dicitur didascalicum, quo Boecius utitur in libro de consolatione, ubi Philosophia magistra Boecio discipulo loquitur (fol. 138r).

${ }^{44}$ Kommentar zu Boethius Consolatio, Ed. Crespo, 59, 28-30. Zur Datierung: Minnis / Scott, 315-316.
} 
Paulus Burgensis (ca. 1343-1435) unterscheidet zwei Teile seines Scrutinium scripturarum: Der erste sei ein Dialog, da er den Disput zwischen einem Christen und einem Juden inszeniert; der zweite sei more didascalico, weil der konvertierte Jude als Schüler fragt ${ }^{45}$.

Der didaktische Wert der Gesprächsform wird oft von Dialogautoren betont. Anselm von Canterbury, Engelbert von Admont, der Verfasser des Malogranatum, Richard FitzRalph und Michael von Prag weisen in ihren Prologen darauf hin ${ }^{46}$. Honorius Augustodunensis sieht im Dialog die geeignete Lehrmethode zur Einführung in ein Thema:

Cuius stilum ideo verti in dialogum quia summis philosophis, Socrati scilicet et Platoni ac Tullio, nec non nostro Augustino et Boetio, visum est id genus docendi quam maximam vim optinere introducendi ${ }^{47}$.

Richard von St. Victor, der seine Abhandlung De Emmanuele im ersten Buch als Traktat und im zweiten als Dialog gestaltet, rechtfertigt den Wechsel zur Dialogform mit deren didaktischem Wert:

Sub forma autem dialogi totam subsequentis operis seriem digessi, eo quod hic modus dicendi vel docendi prae caeteris sit, vel ad audiendum iucundior, vel ad persuadendum efficacior ${ }^{48}$.

Die Bezeichnungen der zwei anderen Dialogformen, genus dragmaticon und enarrativum, zeigen deutlich, wovon Wilhelms Klassifizierung ihre Inspiration nimmt, nämlich aus einer Einteilung der literarischen Werke, die auf Aristoteles zurückgeht und über den spätantiken Grammatiker Diomedes und Isidor von Sevilla das Mittelalter erreichte ${ }^{49}$. Nach ihr werden die Werke, je nachdem, ob sie in Personensprache, Autorsprache oder zwischen beiden alternierend geschrieben sind, in drei genera elocutionis (activum, passivum und mixtum) gegliedert. Die Namen der drei Genera variieren, das genus activum (nur Personensprache) wird auch

45 Paulus Burgensis, Scrutinium scripturarum: Secunda vero pars more procedit didascalico in qua fidelis post fidem susceptam tamquam discipulus de quibusdam in sacris testimoniis scripturarum contentis scrutando miratur et a magistro iam in catholica doctrina erudito horum declaracionem seu intellectum devote petit, a quo horum declaracionem recipiens devotior redditur (fol. $2 \mathrm{r}-2 \mathrm{v}$ ); Unde sic prima pars fuit dyaloga quasi inter duos disputative acta sic ista secunda sit dydascalica quasi inter magistrum et discipulum ad ipsius discipuli erudicionem tractata (fol. 128r). Siehe auch unten 50.

46 Vgl. die Zitate unten 44-45, 47.

47 Honorius Augustodunensis, Clavis physicae, Ed. Lucentini, prol., 8-11, p. 3.

48 Richard von St. Victor, De Emmanuele, PL 196, 633.

49 Vgl. von Moos, „Gespräch“, 213-220; Klopsch, Dichtungslehren, 44-47; Haye, Das lateinische Lehrgedicht, 39-44. 
häufig genus dramaticum genannt ${ }^{50}$. Die Aufführbarkeit spielt jedoch beim genus dramaticum keine Rolle, nur die Darbietungsform Personensprache ist entscheidend, was Wilhelms Verständnis von dragma als Frage erklärt. Die Klassifizierung von Dialogschriften nach diesem Schema war nicht eindeutig. Ciceros De amicitia wurde z.B. in einem Accessus zum genus mixtum gerechnet, weil der Autor in der Widmung das Wort ergreift ${ }^{51}$. Auch Boethius' Consolatio und Gregors Dialogi erscheinen in einer Scholie als Beispiele des stilus mixtus ${ }^{52}$. Wilhelm ließ sich wohl von dieser bekannten Einteilung der Darbietungsformen leiten. Sie eignete sich gut, um zwischen den wohlbekannten Frage-Antwort-Dialogen ${ }^{53}$, die ausschließlich die Personensprache einsetzten, und einem Dialog wie der Consolatio, in dem auch der Autor zur Sprache kommt, zu unterscheiden. Dabei ersetzte er das genus mixtum durch ein genus didascalicum, das der Lehrsituation in Boethius' Dialog Rechnung trug ${ }^{54}$.

Es bleibt zu klären, was Wilhelm unter genus enarrativum verstand. Seine Beschreibung scheint zwar zu einer Diatribe zu passen, sie dürfte jedoch eher von seiner Lehrtätigkeit und vom Kontext der Klassifizierung aus zu erklären sein: Er hatte nämlich nicht nur die Consolatio philosophiae glossiert, sondern ebenfalls die lateinische Übersetzung von Platos Timaeus. Nun kommen in Calcidius' Übersetzung lange Reden vor, die sich vom schnellen Wechsel der Fragen und Antworten unterscheiden und keine Lehreransprachen sind (vor allem die lange, abschließende

50 Vgl. Wilhelm von Conches, Dragmaticon, Ed. Ronca, ,Introduction“, xI-xiII.

51 In einer Fassung des Accessus III, überliefert in einer Handschrift des 15. Jahrhunderts: Si librum in se totum consideremus, utitur auctor mistico [sic, statt mixto] genere loquendi, quia, partim in sua persona, partim per personas introductas loquitur (Accessus zu Ciceros De amicitia, Ed. Pellegrin, 293). Im Accessus I (in der kurzen Rezension 1, 278) wird es hingegen als carmen dragmaticum definiert.

${ }^{52}$ Tria sunt genera stilorum: exagematicus, dramaticus, mixtus. Exagematicus stilus est ubi poeta solus loquitur, ut in Lucano et in Apokalipse. Drammaticus stilus est ubi poeta nihil sed introducte locuntur persone, ut in Terentio et in Canticis Canticorum, mixtus stilus est ubi poeta cum aliquibus personis introducitur, sermocinans ut in Boecio et in Dialogo (Clm 19475, 12./13. Jahrhundert, zitiert von Villa, „I Classici“, 504).

${ }^{53}$ Im Umfeld Wilhelms entstand ein solcher Dialog, die Quaestiones naturales des Adelard von Bath, die er gut kannte. Dieser Titel war nach Wilhelms Verständnis von dra $(\mathrm{g}) m a$ äquivalent zu seinem Dragmaticon. Zu beiden Werken und ihre Beziehungen vgl. Speer, „Ratione duce.“

54 Dies ist freilich eine Eigenart Wilhelms, denn in der Regel wird das didascalicum als eine Spezies des genus enarrativum betrachtet oder tritt gar an dessen Stelle als genus didascalicon, z.B. in Grecismus des Eberhard von Béthune (vgl. Haye, Das lateinische Lehrgedicht, 41-42). Die reichlich konfusen ersten Sätze in dem Abschnitt der Glosae super Platonem scheinen nahezulegen, dass alle collocutiones zum genus mixtum gehören. Es handelt sich jedoch wohl um eine spätere Interpolation. 
Rede des Timaeus). Vermutlich hat Wilhelm an sie gedacht, als er von der continua oratione inter loquentem et audientem schrieb. In diese Richtung zeigt ebenfalls eine Glosse aus dem sogenannten Glossarium Amplonianum secundum, das in einer Handschrift des 9. Jahrhunderts überliefert ist. In ihr werden drei verschiedene Bedeutungen des Wortes dialogus unterschieden: Dialogus liber disputationum uel narratio reciproca uel interlocutiones propter narrationem..$^{55}$ Die ,gegenseitige Erzählung“ bezeichnet wahrscheinlich, wie Wilhelms genus enarrativum, Dialogschriften mit ausführlichen Redeanteilen der Sprecher.

Demzufolge verwendet Wilhelm vor allem formale Kriterien (Personensprache, lange narrative Textabschnitte), die sich freilich mit inhaltlichen Kriterien (Lehrgespräch) kreuzen. Zwei von Wilhelms Kategorien sind wohl im Hinblick auf die kommentierten Werke (Consolatio, Timaeus) entwickelt worden. Relevanter für die Untersuchung der mittelalterlichen Dialoge ist die dritte, das genus dragmaticon inter interrogantem et respondentem. Sie war zweifelsohne eine für Wilhelm noch produktive Dialogform, denn er selbst nannte seinen Dialog Dragmaticon. Seine Auslegung von dragma als Frage fand durch zwei Autoren, die sie aufnahmen, Petrus Helias ${ }^{56}$ und Johannes Balbi ${ }^{57}$, weite Verbreitung ${ }^{58}$. Sie könnte noch den Titel Dragmalogia für einen Dialog des Giovanni Conversini (R71e) inspiriert haben ${ }^{59}$.

${ }^{55}$ Glossaria, Ed. Goetz, 5, 286.

56 Invenitur etiam dragma matis tercie declinationis et est, interrogatio; unde dragmaticum genus loquendi dicitur quasi interrogativum' quod fit per interrogationem et responsionem (Petrus Helias, Summa super Priscianum, Ed. Reilly, 158, 58-61).

${ }_{57}$ Catholicon, s.v. Dragma - atis tercie declinationis per g scriptum est questio sive interrogacio. Hinc dragmaticus -ca-cum id est interrogativus. Unde quoddam genus loquendi dicitur dragmaticum scilicet quod fit inter interrogantem et respondentem (fol. 144r); s. v. Hermeneuticus: ... dragma-atis, quod est interrogacio ...; dragma -tis, quod est questio (fol. 185r).

${ }^{58}$ Vgl. Belege bei LBoh 2, 285 und LNed 3, D735. Hinzu kommt, dass drama zum Teil als Bezeichnung für ein Werk in Personensprache missverstanden und für einen Dialog verwendet wurde: Siehe oben 41, Anm. 51 und MLW 3, 1002.

${ }^{59}$ Unter den erhaltenen Codices aus der Bibliothek Conversinis findet sich eine Abschrift des Dragmaticon Wilhelms aus dem 13. Jahrhundert, heute Firenze, BML, Ashburnham 173, fol. 1v-41r (vgl. Gargan, „Per la biblioteca“, 369-370). Nason sieht die Beziehung zum mittelalterlichen Verständnis des genus dramaticum als Personensprache, ist aber auch der Meinung, die Wortschöpfung entspreche dem Brauch an der Universität von Pavia, mit der lateinischen Sprache sehr frei umzugehen, und sollte auf die kreative Sprache Conversinis in diesem Werk hinweisen (Nason, „Note“, 43-46). 


\subsection{Interrogationes et responsiones}

Wilhelms Klassifizierung wurde von Johannes Balbi in sein Catholicon aufgenommen, allerdings an unerwarteter Stelle (s. v. Hermeneuticus), und ist nicht als Dialogtypisierung erkennbar. Der Text lautet:

Sunt enim tria principalia genera loquendi, scilicet dragmaticum, didascalicum, hermeneuticum sive enarrativum. Dragmaticum est quod inter interrogantem et respondentem versatur, quod scilicet descisum est frequenti interrogacione ut in dyaletico tumultu, et dicitur dragmaticum quasi interrogativum a dragma -atis, quod est interrogacio. Didascalicum est, quod consistit inter doctorem et discipulum, et dicitur didascalicum quasi doctrinale a didascalo, quod est doctor vel magister ${ }^{60}$. Hermeneuticum sive enarrativum est, quod consistit inter continuam orationem decurrentem et audientem, ubi unus continue loquitur, alter vel alteri tacent et audiunt et difert a didascalico in hoc, quod illud sit de doctrina, illud vero minime est doctrinale secundum Hug< $<$ utionem $>$. Vel secundum alios dicitur, quod tria sunt genera loquendi, scilicet didascalicum, dragmaticum et hermeneuticum. Didascalicum est doctrinale a didascalo doctore et hoc utitur inter magistrum et discipulum ut patet in Donato. Et iste modus tractandi dicitur socraticus, quia Socrates primo fuit usus dialogo, id est, duali sermone introducendo unum querentem et alterum respondentem. Hunc autem modum tenet Gregorius in Dyalogo et ego tenui in Questionibus anime ad spiritum, in quodam libro quem compilavi in Theologia, ubi anima tamquam discipuli formam sumens interrogat et spiritus tamquam doctor respondet. Dragmaticum id est interrogativum inter disputantes versatur ut in dyaletica et dicitur a dragma -tis, quod est questio, ubi indicat qui respondet. Hermeneuticum id est interpretativum locum habet in causis ubi est sermo continuus et iudex ordinarius qui causam decidere debet $^{61}$.

Diese Einteilung weist etliche Berührungspunkte mit Wilhelms Typisierung auf (die Interpretation von dragma und von didascalicus, die Namen der Genera), sie ist jedoch nicht mehr als Klassifizierung der Dialogschriften zu erkennen. Außerdem nimmt Johannes zwei verschiedene Einteilungen mit denselben Bezeichnungen für die Genera vor. In der ersten ist nur das genus dramaticum als Dialog zu erkennen, die zwei anderen Genera scheinen sich eher auf Ansprachen oder ununterschieden auf Ansprachen und Dialogschriften zu beziehen. In der zweiten Gliederung

${ }^{60}$ Siehe die Definition von didascalicus, oben 39, Anm. 43.

${ }^{61}$ Catholicon, fol. 185r. Im Druck erscheint durchgängig hermenenticus statt hermeneuticus. Die Interpunktion wurde von mir dem heutigen Gebrauch angepasst. 
können Werke in Dialogform unter zwei Genera vorkommen. Im genus dramaticum wird ausdrücklich auf das Streitgespräch hingewiesen. Unter dem genus didascalicum benutzt Johannes sogar ausdrücklich das Wort dialogus, das er als Gespräch unter Personen definiert, von denen eine fragt und die andere antwortet. Das Vorkommen von Figuren (fiktiven Gesprächsteilnehmern) unterscheidet wohl die dialogi von anderen Werken in Frage-Antwort-Form innerhalb dieser Gruppe, denn Donat wird zwar als Beispiel für das genus didascalicum angeführt, aber nicht ausdrücklich als dialogus. Als Beispiele werden genannt Gregors des Großen Dialogi und Johannes' eigenes Werk Dialogus de quaestionibus animae ad spiritum (R31).

Die Erweiterung von Wilhelms Definition des Dialogs als Frageund-Antwort-Form mit dem Hinweis auf Figuren bei Johannes Balbi hängt freilich von der Interpretation eines Textes ab, der ähnlich wie Isidor unterschiedliches Material versammelt und keine erschöpfende und konsequente Systematik anstrebt. Diese Interpretation findet aber bei etlichen mittelalterlichen Autorenaussagen Rückhalt ${ }^{62}$ :

Et quoniam ea quae per interrogationem et responsionem investigantur, multis et maxime tardioribus ingeniis magis patent et ideo plus placent, unum ex illis qui hoc flagitant, qui inter alios instantius ad hoc me sollicitat, accipiam mecum disputantem, ut Boso quaerat et Anselmus respondeat hoc modo ${ }^{63}$.

... visum est mihi congruum hanc quaestionem exsequi more dialogi, ut Judaeus quaesivit et ego respondi ${ }^{64}$.

Quapropter placuit illis paucas litteralis scientiae regulas memoriae causa per interrogationes et responsiones excerpere ${ }^{65}$.

Ut autem competentius exempla ordinarem, more dialogi duas introduxi personas, novicii videlicet interrogantis et monachi respondentis $^{66} \ldots$

Hunc tractatum, instigante conscientia, propter simpliciores quosque simplicibus verbis de sanctorum dictis compilavi per modum cuiusdam

${ }^{62}$ Auch die antike lateinische Rhetorik erwähnte die Organisation des Textes in Fragen und Antworten als charakteristisch für den Dialog. Um die Gattung Dialog von benachbarten Formen, die sich ebenfalls der Fragen und Antworten bedienten, zu unterscheiden, fügten die antiken Rhetores als weitere Merkmale das philosophische Thema und den eleganten, aber einfachen Stil, der den Ton des kultivierten Gesprächs nachahmt, hinzu. Dazu vgl. Aygon, „Le dialogue“, 201-208.

${ }_{63}$ Anselm von Canterbury, Cur Deus homo, in: Opera, Ed. Schmitt, Bd. 2, 48.

${ }^{64}$ Odo von Cambrai, Disputatio contra Fudaeum Leonem nomine, PL 160, 11038.

${ }_{65}$ Alcuin, De grammatica, PL 101, 854B.

${ }^{66}$ Caesarius von Heisterbach, Dialogus miraculorum (R16), Ed. Strange, 2. 
dialogi, in quo anima devota, veritatis aeternae discipula, meditando interrogat, et homo interior mentaliter loquendo respondet ${ }^{67}$.

Cum igitur, sicut dicit Seneca, ad instruendum hominem de veritate vitae \& morum difficilis \& longa via sit per doctrinam \& dogmata, brevis verò $\&$ facilis per praecepta \& exempla, propter hoc Concupiscentia sensualis in verbis subsequentis collationis causá brevitatis inducitur tanquam interrogans, \& ex dictis Philosophorum, qui in dogmate \& doctrina bonorum morum \& virtutum clari habentur, ex ipsorum sententiis atque dictis, quasi vice Rationis responsio subsequetur ${ }^{68}$.

... Dialogum censeo appellandum. Peto enim, ut per interrogationem et per responsionem fiat ${ }^{69}$.

Quia vero per interrogacionem et responsionem modus tradendi videtur multis facilior licet sit prolixior, unum de meis mihi predilectum discipulum quasi mecum disputantem accepi ${ }^{70} \ldots$

Hoc opus (...) habens hanc formam quo Iohannes censeatur interrogans et Ricardus habeatur sentencians sive suadendo respondens ${ }^{71}$.

... in quo opere (...), intento dialogice procedendo tractare, ut assumpto discipulo Petrus nomine mihi de sacramento eukaristie opponenti et inquirenti determinando respondeam, quod sanctorum doctorum prodit auctoritas et vive rationis consonancia attestatur ${ }^{72}$.

Hoc opus autem per modum dyalogi quasi collocucionem quandam unius querentis, alterius respondentis conscripsi, quia istum stilum delectabiliorem et utiliorem lectori existimavi ${ }^{73}$.

Den Aussagen kann man entnehmen, dass die Gliederung in Fragen und Antworten nicht genügte, um eine Schrift als Dialogus zu bezeichnen. Jeder der zitierten Autoren fügt hinzu, dass sie Figuren in den Mund gelegt werden: Manchmal sind es allegorische Figuren (Ratio und Concupiscentia), manchmal namentlich genannte, historische Personen (Boso und Anselmus), manchmal allgemein gehaltene Figuren (Judaeus, Discipulus, Pater, Filius), manchmal ist der Autor eine von ihnen (bei Anselm, Odo von Cambrai und Richard FitzRalph).

${ }^{67}$ Bonaventura, Soliloquium (R27), Ed. Quaracchi, prol. 4 (Bd. 8, 29).

${ }^{68}$ Engelbert von Admont, Dialogus concupiscentiae et rationis (R33), Ed. Hueber, 68.

${ }^{69}$ Wilhelm von Ockham, Dialogus (R52), Ed. Miethke, 1 Dial. prol.

${ }^{70}$ Richard FitzRalph, Summa de quaestionibus Armenorum (R57a), Ed. Gorman, ep., Z. 104-106.

${ }_{71}$ Richard FitzRalph, De pauperie Salvatoris (R57b), Ed. Poole, 274, 12-14.

${ }^{72}$ Nicolaus Radclyf, De viatico salutari animae inmortalis (R64b), fol. 144va-b.

${ }^{73}$ Michael von Prag, De quatuor virtutibus cardinalibus (R74a), Ed. Storey, 113, 109-111. 


\subsection{Dialogus als Darstellungsform}

Ein weiterer Aspekt ist in den zitierten Aussagen auffällig: Die Autoren bezeichnen immer wieder ihre Vorgehensweise als Darstellungsform eines Themas, wofür sie Wendungen wie forma oder modus tradendi (FitzRalph) oder immer wieder per modum dialogi (Bonaventura, Malogranatum, Michael von Prag) benutzen. Dafür lassen sich weitere Beispiele anführen:

Hanc vehementer affectans presentem libellum per modum dyalogi ad honorem Dei et beate Virginis Marie et omnium beatorum spirituum nec non ad consolationem anime et spiritus mei et sociorum meorum et Ecclesie sancte Dei ex diversis sanctorum sententiis et maiorum meorum dictis et exemplis diligenti studio compilavi ${ }^{74}$.

Cum huiusmodi mordacibus invidis volo disserere et ipsorum per modum dialogi machinamenta frivola confutare ${ }^{75}$.

Et quia multi delectantur in loquela dialogi, moventur a deo duas personas adducere, scilicet veritatem atque mendacium, que per modum disputacionis loquuntur in ista materia alternatim ${ }^{76}$.

... universali sapientum collegio iudice constituto, elucidandae veritatis gratia, verbis planis, et in duplicato sermone persuasionibus, ex variis illius novi casus circumstantiis excogitatis, in utraque parte trado disputandum, atque per modum dialogi ventilandum ${ }^{77}$.

... in hoc opusculo de custodia virginitatis uel castitatis per modum dyalogi uel colloquii edito $^{78}$.

... duos tractatus conflavi (...) unum pro et contra dictum Raimundum (...) et alium contra dictos defensores heresum, observando dialogi modum, ut in eis illius Raimundi hereses et errores et horum eius sequacium presumptiones et temeritates discernantur ${ }^{79} \ldots$

Diese Aussagen zeigen, dass die Verfasser zwischen dem mündlichen Gespräch, einer möglichen Bedeutung des Wortes dialogus, und der schriftlichen Gesprächsform genau unterscheiden. Besonders klar stellt dies der Autor des Malogranatum heraus: 371.

${ }^{74}$ Johannes Balbus, Dialogus de quaestionibus animae ad spiritum (R31), Ed. Grabmann

${ }^{75}$ Johannes von Hildesheim, Dialogus inter directorem et detractorem (R62), Ed. Staring, 338, 36-37.

${ }^{76}$ John Wyclif, Dyalogus (R66a), Ed. Pollard, 1, 6-9.

77 Heinrich von Langenstein, Epistola pacis (R70), Druck Helmstedt 1778, III.

${ }^{78}$ Michael von Prag, Dyalogus de custodia virginitatis (R74b), München, BSB, Clm 18638, fol. 1r.

${ }_{79}$ Nicolaus Eymericus, Dialogus contra Lullistas (R76), Ed. Puig i Oliver, 143, 46-50. 
Sciendum est quod colloquia edificatoria ex ore seniorum ad iuniores prolata magis instruunt et edificant quam simplex lectio. Quod affirmat beatus Gregorius cum dicit collocutionis vox plus quam lectionis sermo torpencia corda excitat. Hoc igitur attendens in hoc tractatu per modum dyalogi videlicet interrogantis et respondentis procedere disposui, hoc est patris spiritualis respondentis et instruentis, filii vero spiritualis interrogantis et informationem recipientis ${ }^{80}$.

Weil ihm die besondere Autorität des gesprochenen Wortes in der monastischen Unterweisung klar ist, wählt er eine Darstellungsform, die auf Fragen und Antworten basiert und dadurch die mündliche Unterhaltung evoziert.

\subsection{Gregorius Dialogus}

Der Verfasser des Malogranatum bezieht sich ausdrücklich auf Gregor den Großen, um sein Vorgehen zu begründen. Auch Konrad von Hirsau nahm Gregors Dialogi als Beispiel für eine bestärkende Funktion der Dialogform und Johannes Balbi erwähnt sie als Beispiel eines Dialogs. Sie stehen damit nicht allein. Föcking hat anhand der Belege in der Datenbank GETEDoc beobachtet, dass bis zum 4. Jahrhundert das Wort dialogus mit den Werken Ciceros in Verbindung erscheint. Diese Assoziation kommt nach Augustinus (354-430) nicht mehr vor. Ungefähr ab Isidors Lebzeiten wird dialogus wieder mit einem bestimmten Autor in Zusammenhang gesetzt: mit Gregor dem Großen ${ }^{81}$. Es gibt weitere Anhaltspunkte dafür, dass Gregors Werk bevorzugt mit dem Titel Dialogus in Verbindung gebracht wurde und somit diesen Begriff mitprägte. Der bereits erwähnte Vocabularius Ex quo, aus den ersten Jahren des 15. Jahrhunderts erklärt: Dyalogus est sermo duorum vel liber Gregorii, in quo habetur vita Benedicti ${ }^{82}$. Johann von Jenstein (1347/48-1400) beruft sich ausdrücklich auf Gregor bei der Benennung seines Werkes: Incipit liber dyalogorum ad honorem beati Gregorii sic intitulatus ${ }^{33}$. Noch bezeichnender

\footnotetext{
${ }^{80}$ Malogranatum (R55), Druck Hain 7449, fol. 6va.

81 Föcking, „Dyalogum“, 82-83. Diese Angaben wurden in der aktualisierten Fassung der Datenbank Library of Latin Texts (Zugang über www.brepolis.net) überprüft.

${ }^{82}$ Ed. Grubmüller et al., D 292 (Bd. 3, 768). In einer anderen Fassung: est sermo duorum vel dicitur liber sancti Benedicti.

83 So lautet die Praescriptio in der Hs. Vaticano, BAV, Vat. lat. 1122, hier fol. 86v., die auf den Autor zurückgeht, vgl. R67a.
} 
ist der Beiname Dialogus für Gregor ${ }^{84}$. Er ist zuerst bei Johannes von Damaskos (ca. 650-ca. 750) anzutreffen ${ }^{85}$, im 10. Jahrhundert bezeugt Liutprand von Cremona, dass dieser Beiname in Konstantinopel noch geläufig war ${ }^{86}$. Im Westen erwähnt Hugo von St. Victor (ca. 1096-1141) in einer Papstliste Gregorius dialogus ${ }^{87}$.

Gregors Dialoge gehören wohl zu den meistgelesenen Werken des Mittelalters. Sie wurden häufig zitiert, zwei Mal versifiziert, bereits im 8. Jahrhundert ins Griechische und im Laufe des Mittelalters ins Kirchenslawische, ins Arabische und in westliche Volkssprachen (Isländisch, Anglonormannisch, Nordfranzösisch, Katalanisch, Kastilisch, Portugiesisch) übersetz ${ }^{88}$. Wir werden noch auf die Frage ihrer Vorbildfunktion eingehen ${ }^{89}$.

\subsection{Dialog und Disputatio}

Bisher wurden zwei Bedeutungen von dialogus besprochen: das Gespräch (colloquium, bei Isidor und in Glossaren) und die Abfolge von Fragen und Antworten (bei Wilhelm von Conches und in Aussagen von Dialogautoren). Eine dritte Bedeutung ist Johannes Balbi zu entnehmen, der das Genus dramaticum mit dem dyalectico tumultu verglich und spezifizierte, dass es inter disputantes versatur ${ }^{90}$. Diese Bedeutung von dialogus als Streitgespräch ist in weiteren Quellen zu finden.

Die Gleichsetzung von dialogus und disputatio kommt zum ersten Mal bei Augustinus vor: a disputatione dialectica nomen accepit, quoniam disputatio graece dialogus vel dialexis appellatur ${ }^{11}$. Das Wort disputatio kann bei Augustinus zwar auch eine Erörterung in Traktatform oder eine Predigt bezeichnen $^{92}$, aber hier ist eher eine Diskussion in Gesprächsform

${ }^{84}$ Die Verwendung des Werktitels als Beiname mutet sonderbar an, man soll jedoch bedenken, dass Dialogus als Beiname, vor allem im griechischsprachigen Raum, bekannt war: ThLL Onomasticon C-D 126, 63-69.

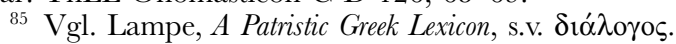

${ }^{86}$ Liutprand von Cremona, Relatio de legatione Constantinopolitana, Ed. Chiesa, 22, 343-347 (p. 196): Romanus enim clericus, postmodum universalis papa Gregorius, qui a vobis appellatus est Dialogus.

${ }^{87}$ Hugo de Sancto Victore, Libellus de formatione arche, Ed. Sicard, 2, 2, 106, S. 130.

88 Dufner, Die Dialoge, 29-45.

89 Siehe unten 84-88, 91-93.

90 Catholicon, s. v. Hermeneuticus, siehe das ausführliche Zitat oben 43.

91 Aug. c. Cresc. 1, 14, 17.

${ }_{92} \mathrm{Zu}$ den Bedeutungen des Wortes bei Augustinus vgl. Fuhrer, „Disputatio“. 


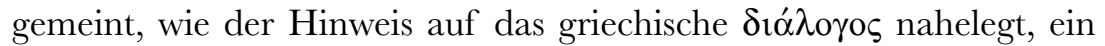
Wort, das bei christlichen Autoren häufig Streit(gespräch) bedeutet ${ }^{93}$. Augustinus selbst bezeichnet häufig sowohl seine theologischen Streitgespräche mit Häretikern als auch ihre schriftliche Niederlegung als disputatio $^{94}$. Die Gleichsetzung zwischen dialogus und disputatio findet sich bei Beda $(672 / 73-735)^{95}$ und häufig in Glossaren wieder: Dialogus (...) disputatio; duorum disp. Graece ${ }^{96}$; Dialogus: disputatio vel liber disputationis ${ }^{97}$; Dialogus: disputatio ${ }^{98}$; Dialogus: liber duorum disputantium ${ }^{99}$; Dialogus: duorum disputantium disputatio ${ }^{100}$. Ebenfalls bei Papias: Dialogus duorum disputatio uel plurium. Nam dia duo: logus sermo graece interpretatur disputatio ${ }^{101}$.

Auch Wyclif setzt den Dialog mit dem Disput zwischen zwei konträren Positionen gleich:

Et quia multi delectantur in loquela dialogi, moventur a deo duas personas adducere, scil. veritatem atque mendacium, que per modum disputacionis loquuntur in ista materia alternatim ${ }^{102}$.

Matthaeus von Krakau beschreibt den Disput von Ratio und Conscientia als Zweikampf:

Idcirco visum est mihi (...) audita, lecta et cogitata et quae Deus adhuc dare potest, prout ipse iuvare dignabitur, in unum quasi duelli circulum comportare, et utriusque partis motiva quadam disputationis lucta collidere, si forte ex hac concertatione magis appareat, quae pars fortiores rationes habeat et per consequens, cui homo magis debeat consentire. Et quia in duello vel luctu debet esse pars invadens, persona defendens et arbiter definiens, sit ratio, quae semper deprecatur ad optima, aggrediens; sit conscientia, vel remordens, vel timida, se defendens, illa est enim, quae communiter a communione retrahit vel retrahitur, sit voluntas superarbiter iudicans, quae earum triumphet, et ex hoc eligens quid sit agendum ${ }^{103}$.

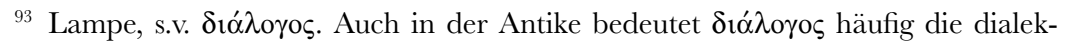
tische Auseinandersetzung mit Darstellung verschiedener Standpunkte, vgl. Aygon, „Le dialogue“, 198-199. Für disputatio in dieser Bedeutung bei antiken Autoren, vgl. ebda., 201.

94 Vgl. Fuhrer, „Disputatio“, 507.

${ }^{5}$ Dialogos graece; disputatio latine (Beda, De orthographia, Ed. Jones, Opera didascalica Bd. 1, 21, 341).

${ }_{96}$ Glossarium Ansileubi in: Glossaria. Bd.1, 25 u. 26, 174.

${ }^{97}$ Glossarium Arma, in: Glossaria. Bd.2, 57.

${ }_{98}$ Glossarium Abstrusa, in: Glossaria. Bd.3, 30.

99 Glossarium Abba, in: Glossaria. Bd.5, 101, 52.

${ }^{100}$ Glossarium AA, in: Glossaria. Bd.5, 433, p. 217.

$101 \mathrm{ND}, 91$.

102 Wyclif, Dyalogus (R66a), Ed. Pollard, 1, 6-9.

${ }^{103}$ Matthaeus von Krakau (R75a), Ed. Seńko - Safrański, 368. 
Paulus Burgensis charakterisiert den ersten Teil seines Scrutinium Scripturarum, der als Streitgespräch gestaltet ist, als pars dyaloga, das Vorgehen der Figuren als dyalogice concertando ${ }^{104}$.

Ein Blick in die Titelgebung im Zeitraum 1200-1400 ist ebenfalls vielsagend. Der Titel Disputatio kommt zum einen bei Traktaten häufig vor, zum anderen bei Dialogschriften, die eine Auseinandersetzung inszenie$r{ }^{105}$. Bei einigen von ihnen alternieren in der Überlieferung die Titel dialogus und disputatio ${ }^{106}$. Bereits spätantike Autoren benutzen häufig den Titel disputatio neben dialogus für kontroverstheologische Dialogschriften $^{107}$. Ein Einfluss der universitären disputationes auf diese Titelgebung ist angesichts dieser Tradition unwahrscheinlich.

\subsection{Dialog als Zwiegespräch}

In den Definitionen der Glossare kommt häufig die Einschränkung vor, Dialog sei das Gespräch oder der Disput zweier Personen ${ }^{108}$, obwohl andere Autoren (Isidor sowie in seiner Nachfolge Hugo von St. Victor und Konrad von Hirsau) ausdrücklich die Möglichkeit mehrerer Gesprächsteilnehmer nennen ${ }^{109}$. Die falsche Etymologie, die den Bestandteil dia von griechisch $\delta$ óo (statt von $\delta \grave{\alpha}$ ) ableitet, dürfte jedoch weit verbreitet gewesen sein. Sie hat zur varianten Graphie dyalogus sowie zu Wortschöpfungen wie trialogus ${ }^{110}$, tetralogus ${ }^{11}$ oder pentalogus ${ }^{112}$ geführt. In seiner Evidentia tragoediarum Senecae (R47a) unterscheidet Mussato in den

${ }^{104}$ Fol. 128r, siehe oben 40, Anm. 45.

${ }_{105}$ R12, R13, R26, R32e, R32g, R32i, R32k, R321, R32m, R32r, R32t; R33, R37, R53, R59, R79.

${ }^{106} \mathrm{R} 13, \mathrm{R} 36, \mathrm{R} 30, \mathrm{R} 53$.

107 Vgl. P. L. Schmidt, „Zur Typologie“, 111-112.

${ }^{108}$ Neben den unter Abschnitt „Dialog und Disputatio“ zitierten Glossaren siehe oben 33, Anm. 20 und 47, Anm. 82 (sermo duorum), sowie Belege in LBoh 2, 128 und LNed 3, D391.

109 Siehe oben 32-33.

${ }^{110}$ Bei Wyclif (R66b) und im 15. Jahrhundert bei Nicolaus von Cues, Trialogus de possest, Martin von Leibitz, Trialogus de militia christiana und Trialogus de gratitudine benefciorum Dei, Antoninus Florentinus, Trialogus super evangelio, Baptista de Finario, Serapion sive trialogus de contemptu mundi et amore religionis (beide in dem Druck GW 2203). Auch Petrarcas Secretum wurde gelegentlich trialogus genannt, wohl wegen der Anwesenheit von Veritas als Richterin (R56a, ,Titel“).

111 Bei Wipo († nach 1046).

112 Bei Enea Silvio Piccolomini (Pius II.), Pentalogus de rebus ecclesiae et imperii. 
Tragödien nach der Zahl der Sprecher dyalogi, trialogi und tetralogi ${ }^{113}$. Die Theoretiker sahen sich mit dem scheinbaren Widerspruch zwischen dieser Etymologie und der Praxis der Autoren konfrontiert. Während Papias noch Etymologie und isidorische Definition kommentarlos aneinanderreiht ${ }^{114}$, versucht ein Cicero-Kommentator (wohl im 12. Jh.) eine Erklärung:

Genus sermonis est dialogus, dialogus autem est disputatio facta per introductas personas. Nam dia grece, duo dicitur latine, logos sermo vel ratio et in hoc loco dia sonat duo, non immo quin plures introducantur persone quam due, sed inde genus sermonis dicitur dialogus quia bine introducuntur persone $\mathrm{e}^{115}$.

So verfährt auch Johann von Jenstein in seinem Liber dialogorum (R67a), in dem zwar mehr als zwei Personen vorkommen, die aber nur paarweise miteinander diskutieren.

\subsection{Vers oder Prosa}

Im Mittelalter gibt es in Latein wie in den Volkssprachen eine weit verbreitete poetische Textsorte, für deren lateinische Tradition sich die Bezeichnung Streitgedicht eingebürgert hat ${ }^{116}$. Streitgedichte inszenieren den Disput von zwei Figuren (Personen, Tieren, Personifizierungen), die sich als Gegensätze präsentieren. Ihre Auseinandersetzung findet manchmal in der Sentenz eines Richters oder Tribunals eine Lösung. Im Zusammenhang dieser Untersuchung stellt sich die Frage, ob mittel-

113 Sepius quoque per dyalogos, trialogos, tetralogos et deinceps personarum introductarum gemitus, eiulatus, planctus, melodias ceterosque mentis affectus per metra diversis distincta pedibus edit (Ed. Megas, 126, 68-69).

114 Vgl. 33 Anm. 17.

${ }^{115}$ Der Kommentar mit dem Titel Glosule Tullii de amicitia ist in einer Handschrift aus dem 12./13. Jahrhundert überliefert. Edition der Einführung zusammen mit den Accessus zu Ciceros De amicitia, Ed. Pellegrin, 294-298, hier 296. Auffällig ähnlich wird in einer Randglosse zu Juan de Lucenas Libro de vita beata (geschrieben 1463) die Bezeichnung diálogo für ein Gespräch mit vier Teilnehmern erklärt: „Diálogo, palabra greca es, compuesta de dia, quod est duo, et logos, quod est sermo, quasi duorum sermo, que quiere decir fabla de dos. Dirásme tú, cómo, pues, el actor llama diálogo a este, ca yo veo que fablan cuatro: Respóndote que como quiera que son cuatro colocutores, los dos pero fablan solamente, y tornan después de los otros: y en verdad aunque fablan diez mil hombres, siempre se llama diálogo, porque fablan dos no más“ (zitiert bei Briesemeister, „Humanistische Dialoge“, 192).

${ }^{116}$ Literatur zum Streitgedicht in 3, Anm. 10. 
alterliche Rezipienten zwischen Streitgedichten und Prosadialogen als verschiedenen Textsorten unterschieden haben. Ein Weg, dies zu ermitteln, ist die Titelgebung. In seinem Aufsatz über die Streitgedichte behandelt Stotz 44 Texte, die in einem Repertorium („Elenco dei testi citati““) als Anhang aufgelistet werden ${ }^{117}$. Anhand dieser Texte hat Stotz festgestellt, dass die Gedichte meistens den Titel conflictus oder altercatio (jeweils sieben) tragen. Vereinzelt kommen iudicium, certamen, contentio, iurgia, causa, discussio litis (jeweils einmal) und dialogus (vier Mal, Nr. 14, 18, 19 und 33 im „Elenco“) vor. Mit der Ausnahme von dialogus handelt es sich demnach um Wörter, die sowohl den inszenierten Streit als auch den inszenierenden Text bezeichnen ${ }^{118}$. Bei näherem Hinsehen stellt sich dialogus als noch seltener dar. Nr. 14 (Dialogus carnalis et spiritualis hominis) ist nach Angaben von Walther im Codex unicus unbetitelt ${ }^{119}$. Nr. 19 (Dialogus mortis cum homine) wird in den Handschriften conflictus, disputatio oder altercatio genannt ${ }^{120}$. Nr. 33 (der breit überlieferte Dialogus inter corpus et animam) trägt in den von Walther untersuchten Handschriften den Titel disputatio ${ }^{121}$. Demnach bleibt es bei einem einzigen Text mit dem Titel Dialogus, dem Dialogus inter aquam et vinum ${ }^{122}$. Der Eindruck, dass dialogus für Streitgedichte nur selten benutzt wird, lässt sich bei den von Walther im Anhang edierten Texten bestätigen. Von ihnen trägt auch nur einer diesen Titel, der Dialogus Iudei cum Christiano quodam ceco, cui et visus restituitur ${ }^{123}$. Bei den meisten Texten scheint der Titel dialogus eher auf neuzeitliche Drucke und Editionen zurückzugehen ${ }^{124}$. Bei den Prosadialogen bilden die für Streitgedichte typischen Bezeichnungen conflictus und altercatio ebenfalls eine Ausnahme: Nur ein Text trägt sie, nämlich der Conflictus inter Deum et diabolum (oder Altercatio diaboli contra Christum, R3) ${ }^{125}$. Es handelt sich dabei um ein Werk, das Gott und den

117 Stotz, „Conflictus“, Elenco: 181-187.

118 Stotz, „Conflictus“, 165, Anm. 1.

119 Walther, Das Streitgedicht, Anhang VIII, 216-218.

${ }^{120}$ Dies hat eine Anfrage in der Datenbank In principio ergeben.

${ }^{121}$ Walther, Das Streitgedicht, 70-71.

${ }^{122}$ Es ist jedoch nicht klar, ob der Titel in der handschriftlichen Überlieferung zu finden ist, und, wenn ja, in welchen Textzeugen. Der Editor Wright (Latin Poems, 87-92) gibt keine diesbezüglichen Informationen.

${ }^{123}$ Walther, Das Streitgedicht, Anhang XVI, 230-232.

${ }^{124} \mathrm{Ab}$ dem 16. Jahrhundert wird Dialogus häufig als Titel für Gedichte und versifizierte Dramen verwendet, vgl. Ludwig, „Formen und Bezüge“, 63, Anm. 12.

${ }^{125}$ Hinzu kommt die Altercatio inter Divinitatem et humanitatem aus dem 12. Jahrhundert (A 19), ein eigentümlicher Text, in dem die Redebeiträge nicht zur Entwicklung einer Argumentation dienen, sondern zur Charakterisierung der zwei gegensätzlichen Figuren Divinitas und Humanitas. 
Teufel in einem Disput um die Errettung der Menschheit auftreten lässt und sich dadurch von anderen Streitgesprächen unterscheidet, in denen Vertreter zeitgenössischer Gruppen (der Jude, der FranziskanerSpirituale o. Ä.) aktuelle Auseinandersetzungen austragen ${ }^{126}$. Vielleicht sollten die für den Text benutzten Titel diesen Unterschied markieren. Man kann die Contentio de nobilitate (R20) hinzufügen, eigentlich eine Kontroverse, in der zwei Reden aufeinander folgen ${ }^{127}$.

Es gibt allerdings immer wieder Gedichte, die in Themen, Personenwahl und Aufbau Prosadialogen sehr ähnlich sind, aber keines trägt den Titel Dialogus. Zum Beispiel ist De virginitate Mariae, das Rudolf von St. Trond (12. Jahrhundert) zugeschrieben wird, ein Streitgespräch zwischen einem Juden und einem Christen, das im Unterschied zu den Streitgedichten die Figuren nicht lediglich kontrastiert, sondern eine doktrinale Argumentation, in diesem Fall über die Jungfräulichkeit Mariens, entwickelt. Auch selbstbetrachtende Dialoge wurden gelegentlich in Versen abgefasst: Um 1100 entstand der Paraclitus des Warnerius von Basel, um 1193 die Elegia des Heinrich von Settimello ${ }^{128}$. Es gibt sogar einen Traktat über die Frage der päpstlichen Machtbefugnisse, der als Versdialog gestaltet ist, nämlich der Planctus ecclesie in Germania Konrads von Megenberg ${ }^{129}$.

Bei den Marienklagen kommt gelegentlich Dialogus als Titel vor, dabei könnte sich der Einfluss weitverbreiteter Prosatexte bemerkbar machen: des sogenannten Bernhardstraktats (A7), in dem Maria eine Schilderung des Leidens Jesu in den Mund gelegt wird, des Dialogus inter Mariam et animam (R6) und vor allem des Dialogs zwischen Anselmus und Maria (R21). Diese Vermutung sieht sich durch zwei weitere Gedichte bestätigt, die eine ähnliche Situation wie in diesem letzten Text - nämlich das Gespräch zwischen einer Heiligen und einem Mönch - inszenieren und den Titel Dialogus tragen ${ }^{130}$.

Die Untersuchung der Titelgebung legt daher nahe, dass Streitgedichte, Versdialoge und Prosadialoge unterschiedlich bezeichnet werden. Die Ausnahmen sind Texte, die Einflüsse der jeweils anderen Textsorte aufweisen. Konrad von Hirsau bestätigt indirekt diese Ergebnisse: Obwohl

\footnotetext{
${ }^{126} \mathrm{Zu}$ dem Conflictus inter Deum et diabolum und ähnlichen Texten siehe Kap. 6, „Streitgespräche über das Heilsgeschehen und Satansprozesse“.

127 Siehe unten 252-253.

$128 \mathrm{Zu}$ diesen beiden Werken siehe unten 172 und 201.

129 Siehe unten 158, Anm. 150.

130 Siehe unten 204.
} 
er behauptet, Dichter würden Dialoge zur Unterhaltung einsetzen, benutzt er für die Gespräche in den Eclogen die Bezeichnungen altercationes oder sermones.

\subsection{Dialog und Diatribe}

Bei der Kommentierung der Texte Isidors und Wilhelms von Conches wurde die Möglichkeit erwähnt, dass diese Autoren die Ansprache an einen Zuhörer als dialogus ansehen könnten. Bei Isidor stellte sich genauer die Frage, ob er sermo in der Bedeutung ,Predigt' weiterhin als Übersetzung von dialogus ansah. Dies scheint jedoch unwahrscheinlich, denn es fehlen weitere Belege für eine solche Verwendung unter christlichen Autoren. Senecas Dialogi hätten als Vorbild für eine solche Verwendung des Wortes dienen können. Es ist aber unklar, ob sie zu Isidors Zeiten noch in Spanien zirkulierten. In der ersten Hälfte des 12. Jahrhunderts waren sie wohl nur in Süditalien bekannt ${ }^{131}$. Es ist ferner umstritten, seit wann sie diesen Titel, der in der ältesten Handschrift (Montecassino, 11. Jahrhundert) vorkommt, tragen ${ }^{132}$. Im Spätmittelalter zirkulierten sie jedenfalls in Mitteleuropa unter dieser Bezeichnung: Im 13. Jahrhundert wurden sie von mehreren Autoren im Umkreis der Universität Paris zitiert, im 14. Jahrhundert wurden sie eifrig kopiert ${ }^{133}$. Sie hätten demnach dazu führen können, dass die Werkbezeichnung dialogus mit einem diatribischen Text in Verbindung gebracht wurde. Es gibt eine Möglichkeit zu überprüfen, ob dem so war: die Titelgebung. Bei der heuristischen Arbeit wurden mehrere Texte gefunden, die den Titel Dialogus trugen und in Form einer Ansprache geschrieben waren. Allerdings stellte sich heraus, dass die meisten von ihnen erst in der Forschungsliteratur des 20. Jahrhunderts als Dialog bezeichnet wurden ${ }^{134}$. Der Monarchialis des Jacobus von Theramo (A 17) wurde erst von Johannes Trithemius (der den Text vielleicht nicht direkt kannte) dialogus genannt. Ein Einzelfall ist der Dialogus libri vite des Rodrigo Jiménez de Rada (A8), der seinen Titel wohl von einem Schreiber im 15. Jahrhundert bekam. Das einzige andere mittelalterliche Werk, das damit vergleichbar wäre, ist der Dialogus confessionalis Rathers vonVerona (ca. 890-974), der in

131 Vgl. Reynolds, „The medieval tradition“.

${ }^{132}$ Es ist ebenfalls umstritten, was mit dem Titel gemeint ist. Zusammenfassung der Diskussion bei Cupaiuolo, Introduzione, 53-59.

${ }_{133}$ Vgl. Reynolds, „The medieval tradition“.

134 Dies ist der Fall bei A9, A11, A13, A14, A16. 
weiten Teilen diatribische Form aufweist; allerdings kommt darin der angesprochene Dialogpartner immer wieder zur Sprache. Für die von uns untersuchte Zeit scheint eine Verwendung des Titels dialogus für diatribische Texte auszuschließen zu sein ${ }^{135}$.

\subsection{Zusammenfassung der Ergebnisse- Abgrenzungskriterien des Textkorpus}

Die Untersuchung und der Vergleich verschiedener Quellen erlauben wertvolle Einblicke in das mittelalterliche Verständnis von Dialog. Formale, funktionale und inhaltliche Aspekte sind von mittelalterlichen Autoren beobachtet worden:

- Die Darbietungsform der Dialogschriften ist die Personensprache. Dies wird durch die weitverbreitete Erklärung von dialogus als (verschriftetes) Gespräch sowie die Beschreibung der Form als Fragen und Antworten durch fiktive Personen belegt. Textformen wie Predigt oder Diatribe, in denen eine Figur eine zweite, schweigende Person anspricht, werden nicht Dialoge genannt.

- Ältere Werke, die als Dialoge gelesen und kommentiert wurden (Gregors Dialogi, Boethius' Consolatio, Ciceros De amicitia), werden teils dem genus activum (reine Personensprache), teils dem genus mixtum (Verknüpfung von Autor- und Personensprache) zugerechnet. D.h., das Vorkommen von narrativen Elementen wurde in Werken, die eine Modellfunktion einnehmen konnten, beobachtet. Die Autorsprache galt jedoch offensichtlich als sekundär. Die antike Unterscheidung zwischen mimetischen und diegetischen Dialogen findet sich allerdings nicht mehr, es sei denn, ähnliche Kriterien hätten Wilhelm von Conches zu seiner Differenzierung zwischen dem genus dragmaticon und dem genus didascalicum der Dialoge geführt.

- Die Aussagen der Autoren zeigen, dass die von ihnen vielfach erwähnten Fragen und Antworten Figuren zugewiesen werden müssen. Auch die verschiedenen Werke, die als Dialoge gelesen, genannt oder kommentiert werden (die im vorherigen Abschnitt genannten sowie der platonische Timaeus in Calcidius' Übersetzung), lassen Personen auftreten.

${ }^{135}$ Sie ist anscheinend erst in der Reformationszeit verbreitet: vgl. Kampe, Problem „Reformationsdialog“, 87. 
- Es hat sich ebenfalls gezeigt, dass mit dialogus der Prosadialog gemeint ist. Gedichte werden nur in Ausnahmefällen dialogus genannt, meistens nur dann, wenn sie inhaltlich Prosadialogen nahe stehen.

- Dialogus wurde zwar häufig mit Zwiegespräch gleichgesetzt, es wurde jedoch auch beobachtet, dass die Teilnehmer mehrere sein können.

- Auf den didaktischen Inhalt der Dialoge wird immer wieder hingewiesen. Bereits Isidor versteht den Dialog als Textsorte der Gebrauchsliteratur, und zwar im Zusammenhang mit didaktischen Schriften. Wilhelm von Conches, Wilhelm von Aragon und Paulus von Burgos sehen das Lehrer-Schüler-Gespräch als Äußerungsform der didaktischen (didaskalischen) Rede. Auch die Beschreibung der Texte als interrogationes et responsiones setzt sie in Beziehung zur Schulliteratur.

- Eine zweite thematische Linie findet sich in der Beschreibung von Dialogen als disputationes, als Streitgespräche, die konträre Positionen inszenieren.

- Die Funktionen der Dialogform werden vor allem bei Konrad von Hirsau reflektiert, der Autorisierung der Aussagen, Unterhaltung und Bestärkung erwähnt. Der unterhaltsame und gleichzeitig lehrreiche Aspekt der Dialogform wird von vielen Autoren ebenfalls genannt.

Diese Ansichten mittelalterlicher Autoren sollen die Grundlage für die Wahl eines Textkorpus bilden, allerdings eignen sich nicht alle zu diesem Zweck: Es ist z.B. davon auszugehen, dass nicht alle Themen und Funktionen gleichermaßen von den Zeitgenossen vermerkt wurden. Als praktikable Ausgangspunkte bieten sich vorrangig die formalen Kriterien Prosa sowie überwiegende Personensprache mit Zuweisung an Figuren an. ,Überwiegend' bedeutet hier, dass narrative Einschübe zwar prinzipiell möglich, aber quantitativ und strukturell den Textanteilen in Personensprache untergeordnet sein müssen. Dies ist freilich eine Ermessensfrage, die im Zweifelsfall zugunsten einer Aufnahme in das Korpus entschieden werden soll. Prinzipiell muss man anmerken, dass es in diesem Stadium der Untersuchung nicht entschieden wird, was ein Dialog ist. Vielmehr sind die Kriterien so weit gefasst, dass ein breitangelegtes Korpus, in dem auch Grenz- und Übergangsfälle berücksichtigt werden, zustande kommen kann. Dafür wird in Kauf genommen, dass in diese erste Auswahl auch Texte Eingang finden, die sich nach Entwicklung eines Dialogbegriffes als einer nicht dialogischen Textsorte zugehörig erweisen können. Ein zusätzliches Kriterium ist die Sprache: Nur in Latein verfasste Texte werden berücksichtigt. Latinisierungen wären vor allem zur Beurteilung der Beziehungen zwischen 
lateinischer und volkssprachlichen Literaturen wichtig; diese sind jedoch nicht Gegenstand dieser Untersuchung.

Andere Dialogeigenschaften, die in diesem Kapitel eruiert wurden (beobachtete Themen und Funktionen sowie die Beschränkung auf zwei Sprecher), sollen erst anhand dieses Korpus überprüft werden. Sie wurden nämlich zum Teil aus Texten gewonnen, die sich kommentierend mit älteren Schriften befassen. Daher müssen sie erst mit der Praxis der mittelalterlichen Autoren kontrastiert werden. Sie bieten jedoch einen guten Ausgangspunkt für die Typisierung. 